\title{
MATHEMATICAL MODELLING OF TISSUE FORMATION IN CHONDROCYTE FILTER CULTURES
}

\author{
CJ Catt ${ }^{1}$, W Schuurman ${ }^{2,3}$, BG Sengers ${ }^{4}$, PR van Weeren ${ }^{2}$, WJA Dhert ${ }^{3,5}$, CP Please ${ }^{1}$ and J Malda ${ }^{3 *}$ \\ ${ }^{1}$ School of Mathematics, University of Southampton, UK \\ ${ }^{2}$ Department of Equine Sciences, Faculty of Veterinary Sciences, Utrecht University, The Netherlands \\ ${ }^{3}$ Department of Orthopaedics, University Medical Centre Utrecht, The Netherlands \\ ${ }^{4}$ Bioengineering Research Group, School of Engineering Sciences, University of Southampton, UK \\ ${ }^{5}$ Faculty of Veterinary Sciences, Utrecht University, The Netherlands
}

\begin{abstract}
In the field of cartilage tissue engineering, filter cultures are a frequently used three-dimensional differentiation model. However, understanding of the governing processes of in vitro growth and development of tissue in these models is limited. Therefore, this study aimed to further characterise these processes by means of an approach combining both experimental and applied mathematical methods. A mathematical model was constructed, consisting of partial differential equations predicting the distribution of cells and glycosaminoglycans (GAGs), as well as the overall thickness of the tissue. Experimental data was collected to allow comparison with the predictions of the simulation and refinement of the initial models. Healthy mature equine chondrocytes were expanded and subsequently seeded on collagen-coated filters and cultured for up to 7 weeks. Resulting samples were characterised biochemically, as well as histologically. The simulations showed a good representation of the experimentally obtained cell and matrix distribution within the cultures. The mathematical results indicate that the experimental GAG and cell distribution is critically dependent on the rate at which the cell differentiation process takes place, which has important implications for interpreting experimental results. This study demonstrates that large regions of the tissue are inactive in terms of proliferation and growth of the layer. In particular, this would imply that higher seeding densities will not significantly affect the growth rate. A simple mathematical model was developed to predict the observed experimental data and enable interpretation of the principal underlying mechanisms controlling growth-related changes in tissue composition.
\end{abstract}

Keywords: Cartilage, tissue engineering, mathematical modelling, filter culture.

\author{
*Address for correspondance: \\ Jos Malda \\ Department of Orthopaedics \\ University Medical Centre Utrecht \\ PO Box 85500 \\ Utrecht 3508 GA \\ The Netherlands
}

Telephone number: +31887558078

FAX number: +31302510638

E-mail: j.malda@umcutrecht.nl

\section{Introduction}

The limited self-healing capacity of articular cartilage has made the restoration of cartilage defects an important target in the field of regenerative medicine. However, despite many years of dedicated research, few regenerative approaches have successfully been translated to the clinic thus far (Williams et al., 2008). Natural articular cartilage tissue is organised in characteristic depth-related zones, each with distinct physicochemical and biological properties and functions, that work together to impart lowfriction, wear-resistant behaviour that is characteristic of articular cartilage in diarthrodal joints (Hayes et al., 2007; Klisch et al., 2008; Schinagl et al., 1997). One of the likely reasons for the limited clinical success of regenerative approaches is our current lack of understanding of this specific spatial organisation and our inability to induce it in tissue constructs.

During the growth of native articular cartilage cell proliferation and differentiation occur simultaneously (Ofek et al., 2008; Park et al., 2006). The differentiated cells produce collagen and glycosaminoglycans (GAGs), which give structure and body to the tissue. The production of GAGs has been shown to follow the production of early phase collagen, especially of collagen type VI (Ofek et al., 2008), suggesting the long collagen fibres provide the scaffold to the tissue whilst the GAGs provide the bulk to the structure.

In furthering our knowledge about cellular responses and behaviour, in vitro models play a significant role. However, two-dimensional (2D) in vitro models have limitations with respect to phenotypic cell changes, and most 3D models are poorly understood and generally lack the true native 3D environment (Rouwkema et al., 2011). Common 3D in vitro models for cartilage tissue engineering research include a) the alginate bead culture in which cells are suspended in hydrogel beads (Guo et al., 1989), b) the aggregate or pellet culture (Kato et al., 1988), which allows direct cell-cell interactions to further enhance chondrogenic differentiation, and c) the filter culture, in which cells are grown on a permeable filter. Chondrocytes cultured in the last culture system have been demonstrated to synthesise neo-tissue that mimics the extracellular matrix (ECM) found in native cartilage (Yang et al., 2006a). This method has been used to investigate the effects of culture conditions, such as co-cultures of different cell (sub)types or passages (Hayes et al., 2007; Taylor et al., 2009), or the effect of synovial fluid factors on chondrogenesis (Yang et al., 2006b). 
Mathematical simulations can be used to predict biological growth for tissue engineered cartilage (Galban and Locke, 1997) and could provide improved understanding of in vitro growth in chondrocyte filter cultures and insight into the processes by which it is governed. For example, nutrient uptake and diffusion in cartilage tissue engineering have been extensively studied, using a range of mathematical models (for a review see Sengers et al., 2007). These simulations have been extended to account for ECM production on seeded scaffolds (Nikolaev et al., 2010; Obradovic et al., 2000) or in explants (Klisch et al., 2008). In this paper, we examine the effects of ECM production on the growth of chondrocytes in filter culture and compare the predictions of the mathematical simulations with experimental data. Results demonstrate that cell differentiation rates play a more significant role than nutrient transport.

\section{Materials and Methods}

\section{Cell isolation and culture}

Full thickness healthy articular cartilage was harvested from the condyles and patellofemoral groove of a fresh equine cadaver (age 3 years) under aseptic conditions. After overnight digestion using $0.15 \%$ type II collagenase (Worthington Biochemical corporation, Lakewood, NJ, USA) at $37{ }^{\circ} \mathrm{C}$, the cell suspension was filtered $(100 \mu \mathrm{m}$ cell strainer, BD Falcon, Bedford, MA, USA) and washed three times in phosphate-buffered saline (PBS, Invitrogen, Carlsbad, CA, USA). Cells were then resuspended in chondrocyte expansion medium (DMEM, Invitrogen) supplemented with $10 \%$ foetal bovine serum (FBS, Biowhittaker, Walkersville, MD, USA), 100 units/mL penicillin and $100 \mu \mathrm{g} / \mathrm{mL}$ streptomycin (both Invitrogen), and $10 \mathrm{ng} / \mathrm{mL}$ fibroblast growth factor-2 (FGF-2, R\&D Systems, Minneapolis, MN, USA) and counted using a haemocytometer.

Chondrocytes were expanded for 10 days in monolayer cultures $\left(5,000\right.$ cells $\left./ \mathrm{cm}^{2}\right)$ in expansion medium. After expansion, cells were detached using $0.25 \%$ trypsin (Invitrogen), washed with PBS, and seeded at a density of $1 \times 10^{6}$ cells $/ \mathrm{cm}^{2}$ on Millicell filters (Millipore, Bedford, MA, USA) (Hayes et al., 2007; Taylor et al., 2009; Yang et al., 2006a) that were pre-coated with collagen type I (Sigma-Aldrich, St Louis, MO, USA), and cultured for up to 7 weeks ( 49 d) in chondrocyte differentiation medium (DMEM supplemented with $0.2 \mathrm{mM}$ ascorbic acid 2-phosphate (Sigma-Aldrich), $0.5 \%$ human serum albumin (SeraCare Life Sciences, Milford, MA, USA), 1x ITS-X (Invitrogen), 100 units $/ \mathrm{mL}$ penicillin and $100 \mu \mathrm{g} / \mathrm{mL}$ streptomycin, and $5 \mathrm{ng} / \mathrm{mL}$ transforming growth factor- $\beta 2$ (TGF- $\beta 2, R \& D$ Systems). Medium was refreshed twice a week and medium samples were taken and stored for further analysis. Samples of the filter cultures were taken weekly, and then cut in half; one half was processed for histology whilst the other half was used for quantitative assays.

\section{Histological and biochemical analyses}

For histology, samples were fixed in formalin, processed through graded alcohol series and embedded in paraffin. Embedded sections were cut to yield $5 \mu \mathrm{m}$ sections. Sections were stained with Weigert's haematoxylin (Klinipath, Duiven, The Netherlands) and fast green (Merck, Darmstadt, Germany) for cells and with Safranin-O (Merck) for proteoglycans. For biochemical analysis, samples were digested overnight at $56{ }^{\circ} \mathrm{C}$ in a solution containing $250 \mu \mathrm{g} / \mathrm{mL}$ papain (Sigma-Aldrich). Quantification of total DNA was performed by Quant-iT PicoGreen dsDNA kit (Molecular Probes, Invitrogen) using a spectrofluorometer (Biorad, Hercules, CA, USA). The amount of GAG was determined spectrophotometrically after reaction with dimethylmethylene blue dye (DMMB, Sigma-Aldrich) (Farndale et al., 1986). Intensity of colour change was quantified immediately in a microplate reader (Biorad) by measuring absorbance at 540 and $595 \mathrm{~nm}$. The amount of GAG was calculated using a standard of chondroitin sulphate C (Sigma-Aldrich) and by calculating the ratio of absorbances.

The tissue sections were examined using a light microscope (Olympus BX51, Hamburg, Germany) to assess the tissue thickness and the distribution of cells and GAGs. Photographs of all samples were then taken using an Olympus DP70 camera.

\section{Image and data analysis}

The distribution of cells was derived using image analysis software written for this study in MATLAB (MATLAB V7.9.0.529, MathWorks Inc, MA, USA). The tissue samples did not grow as perfectly uniform layers, nor did the shape of the membrane remain flat during processing. Throughout the duration of the experiment, the width of the cell layer is always at least two orders of magnitude greater than the thickness. Therefore, an appropriate approximation is to study the growth as a flat (onedimensional) layer, expanding in the vertical direction. Based on this assumption, the tissue slices were scaled so that the cell position was taken relative to the vertical distance from the membrane at that point (Fig. 1). To do so the images were adjusted so that the lower and upper edges of the tissue were horizontal, assuring no information was lost (as could occur if part of the picture was cut off). The position of each cell was then defined in relation to the adjusted image.

For all time points the pictures of the slices were divided in horizontal bands of approximately $15 \mu \mathrm{m}$. The number of cells in each band was determined and divided by the averaged volume of the band to determine the density of cells and hence the density distribution through the tissue. The total number of cells through the layer of tissue was also calculated at each time point.

During histological analysis a cell could be included in multiple slices and corrupt the data. To correct for this, the observed cell densities were multiplied by a scaling factor, $\zeta$ (Table 1). This scaling factor was derived from the analysis of vertical sections of photographed tissue samples with a width equal to the section thickness (5 


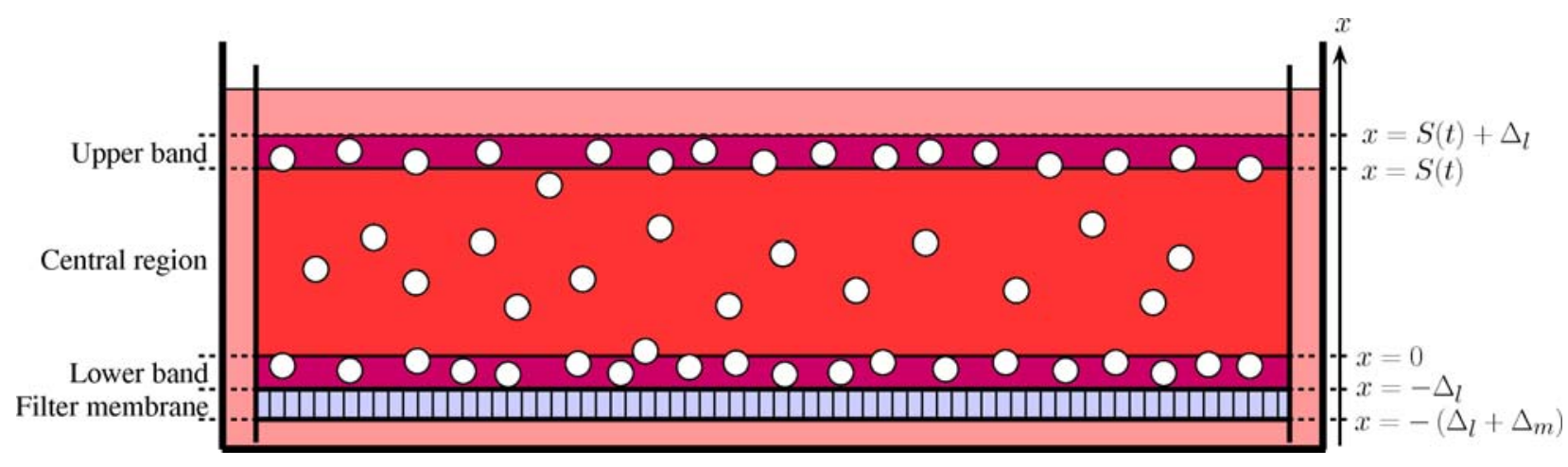

Fig. 1: Schematic representation of the idealised model and modelling notation. The tissue layer is broken up into three regions, the lower layer, the central layer and the upper layer. Both the lower and upper layers have constant thickness, $\Delta_{1}$. The central layer lies in between these two layers and the thickness of the central layer, $S(t)$, increases over time, $\mathrm{t}$, due to growth. We shall therefore define the position where the lower layer and central layer meet to be at $\mathrm{x}=0$ and the position where the central layer and upper layer meet to be at $\mathrm{x}=\mathrm{S}(\mathrm{t})$. Beneath the lower layer is a fourth region, the filter membrane, which has thickness $\Delta_{\mathrm{m}}$. Cells in the upper layer are proliferating whilst those in the lower layer are quiescent. The central layer contains cells producing collagen and GAGs and increases in thickness over time. There are no cells in the filter membrane. The constant thicknesses $\Delta_{1}$ and $\Delta_{\mathrm{m}}$ are given in Table 1 .

Table 1: Values of parameters required for mathematical modelling. The values not from the literature are either directly measured or determined by fitting to the experimental results.

\begin{tabular}{|c|c|c|c|}
\hline \multicolumn{2}{|c|}{ Parameter } & \multirow{2}{*}{$\begin{array}{l}\text { Value } \\
1 \times 10^{-14}\end{array}$} & \multirow{2}{*}{$\begin{array}{c}\text { Units } \\
\mathrm{m}^{2} \mathrm{~s}^{-1} \\
\end{array}$} \\
\hline $\mathrm{D}_{\text {agg }}$ & Diffusion coefficient of aggregate GAGs (Comper and Williams, 1987) & & \\
\hline $\mathrm{D}_{\mathrm{gag}}$ & Diffusion coefficient of GAGs (Obradovic et al., 2000) & $1 \times 10^{-11}$ & $\mathrm{~m}^{2} \mathrm{~s}^{-1}$ \\
\hline $\mathrm{N}_{\text {low }}$ & Density of cells in lower band & $3.32 \times 10^{14}$ & cell $\mathrm{m}^{-3}$ \\
\hline $\mathrm{N}_{\text {up }}$ & Density of cells in upper band & $2.66 \times 10^{14}$ & cell $\mathrm{m}^{-3}$ \\
\hline $\mathrm{R}_{\mathrm{agg}}$ & Aggregation rate of GAGs & $2.05 \times 10^{-2}$ & $\mathrm{~s}^{-1}$ \\
\hline $\mathrm{R}_{\mathrm{col}}$ & Rate of collagen synthesis & $9.75 \times 10^{-15}$ & g cell $^{-1} \mathrm{~s}^{-1}$ \\
\hline $\mathrm{R}_{\mathrm{dif}}$ & Rate of cell differentiation (Sengers, 2005) & $7.10 \times 10^{-6}$ & $\mathrm{~s}^{-1}$ \\
\hline $\mathrm{R}_{\mathrm{gag}}$ & Rate of GAGs synthesis (Sengers, 2005) & $3.78 \times 10^{-16}$ & $\mathrm{~g} \mathrm{cell}^{-1} \mathrm{~s}^{-1}$ \\
\hline$\zeta$ & Cell over count ratio & 0.283 & \\
\hline $\mathrm{F}_{\mathrm{NPro}}$ & Flux of cells from upper band & $3.31 \times 10^{3}$ & cell $\mathrm{m}^{-2} \mathrm{~s}^{-1}$ \\
\hline $\mathrm{Col}_{0}$ & Concentration of collagen (Freed et al., 1998) & $1.23 \times 10^{5}$ & $\mathrm{~g} \mathrm{~m}^{-3}$ \\
\hline$\Phi_{\mathrm{m}}$ & Filter filtration fraction (Millipore, 2009) & 0.5305 & \\
\hline$\Delta_{1}$ & Height of lower and upper bands & $1.5 \times 10^{-5}$ & $\mathrm{~m}$ \\
\hline$\Delta_{\mathrm{m}}$ & Height of filter membrane & $3 \times 10^{-5}$ & $\mathrm{~m}$ \\
\hline $\mathrm{N}_{0}$ & Initial cell density & $3.12 \times 10^{14}$ & cell $\mathrm{m}^{-3}$ \\
\hline $\mathrm{C}_{\mathrm{agg} 0}$ & Initial concentration of GAGs & $7.45 \times 10^{-5}$ & $\mathrm{~g} \mathrm{~m}^{-3}$ \\
\hline $\mathrm{S}_{0}$ & Initial height of central region & $3.6 \times 10^{-5}$ & $\mathrm{~m}$ \\
\hline$\alpha_{\mathrm{cg}}$ & Initial ratio of cell types & 0.059 & \\
\hline $\mathrm{r}$ & Radius of a cell & $7.5 \times 10^{-6}$ & $\mathrm{~m}$ \\
\hline
\end{tabular}

$\mu \mathrm{m})$. The number of cells observed was compared to the number of cells whose centre resided in the section to give the ratio $\zeta$. This value is similar to that computed using the approach of Stockwell (1971) and has the advantage of being independent of nucleus diameter.

The intensity of Safranin-O staining was measured using image analysis software written for this study in MATLAB. The relative distribution of GAGs was determined for each slice and these distributions were averaged to give a single value at each time. Assessing the relationship between the relative distribution of GAGs (as shown by the Safranin-O staining) and the absolute density of GAGs within the tissue is a common problem in biological analysis. We assumed that the concentration of GAGs and intensity of staining are linearly related (Martin et al., 1999). However, the scaling for this relationship may vary between experiments. Thus, the experimental results for the distribution of GAGs were only compared to the mathematical simulations at the end of the culture period at $49 \mathrm{~d}$ and the light intensity to mass of GAG scaling was 
Table 2: Variables used in the mathematical model.

\begin{tabular}{|l|l|}
\hline Variable & Description \\
\hline $\mathrm{x}$ & Distance from the bottom of the central region \\
\hline $\mathrm{t}$ & Time \\
\hline $\mathrm{C}_{\mathrm{agg}}$ & Concentration of aggregate GAGs \\
\hline $\mathrm{C}_{\mathrm{col}}$ & Concentration of collagen \\
\hline $\mathrm{C}_{\mathrm{gag}}$ & Concentration of GAGs \\
\hline $\mathrm{N}_{\mathrm{col}}$ & Density of cells producing collagen \\
\hline $\mathrm{N}_{\mathrm{gag}}$ & Density of cells producing GAGs \\
\hline $\mathrm{U}$ & Velocity of the tissue (tissue displacement rate) \\
\hline$\Phi$ & Extracellular volume fraction \\
\hline
\end{tabular}

determined from the weight of GAG in the tissue from samples taken at that same moment.

\section{Cartilage layer mathematical model}

Both our experimental findings and information regarding the growth of cartilage from the literature were used as a basis for the mechanistic assumptions used in the mathematical simulation to describe cell movement, cell differentiation and ECM production within the growing tissue structure.

The central assumption of the mathematical model is that the cells are separated by the ECM components that are produced. The ECM found in native cartilage tissue is a complex structure consisting of mainly collagen type II and GAGs in terms of volume, but there are various other components that are found in minor quantities, for instance collagen type VI which is found in the matrix directly around the cells in mature tissue, and throughout the matrix in early in vitro tissue formation (Ofek et al., 2008). In this model, we assumed a bimodal ECM composition of collagen (irrespective of type) and GAGs. Therefore, in our simulation, collagen consists of either collagen type II or VI, as a fibrous material that acts to provide strength to the cartilage structure (Davies et al., 2002). Consequently, collagen was thought of as forming a scaffold in which the cells and GAGs are interspersed.

Histological sections indicated that it was appropriate to construct a model with three distinct layers: the lower band, central region and upper band (Fig. 1). Measurements indicated that the number of cells in the lower and upper bands was constant and close to the expected density of confluence, hence both were considered to be a single cell $(15 \mu \mathrm{m})$ thick and have constant cell density, while the central region grows to make up the remaining thickness. The lower band consists of a thin layer of densely packed cells that are situated directly on top of the filter membrane. It was assumed that inhibitory factors prevent these cells from proliferating and creating ECM. Thus, these cells are essentially quiescent, remaining at constant density. Above this is the central region in which the cells are solely focused on ECM production and do not proliferate. Although it is recognised that cells can simultaneously produce collagen and GAGs, to simplify the model we considered separate populations of cells that at any one time can either produce collagen or produce GAGs (Ofek et al., 2008). Thus, the cell population was broken down into collagen producing cells and cells producing GAGs. Furthermore, it was assumed that the fibrous framework for the tissue structure (collagen) must be constructed before it is filled with the ground substance (GAGs). Cells were therefore initially defined as collagen producing cells before differentiating to GAG producing cells, as proposed by (Ofek et al., 2008). Collagen was assumed to be the principal material that determined the distance between cells, while the GAGs were taken to be more passive. Collagen will move with the tissue as the layer expands, while the GAGs will move with the cells and will also be allowed to diffuse through the layer. Mathematical simulations with a single type of GAG were inadequate in predicting both the spatial distribution of GAGs in the tissue and the amount of GAGs in the surrounding medium. In reality, after secretion by the cell GAGs undergo a selfassembly process to form large aggregates. This has been modelled previously by considering separate mobile and immobilized (i.e. bound) GAGs (DiMicco and Sah, 2003; Nikolaev et al., 2010). Extending the model to include two types of GAGs, one smaller that diffuses easily and the other consisting of larger aggregates, which diffuse much more slowly, gave much better predictions. This simple model assumed that the small GAGs would bind to the larger aggregates at a constant rate. In this scenario, growth of the central region will be due to the production of collagen and the GAGs are deemed to adhere to the collagen rather than contribute to the expansion of the layer. Finally, there is an upper band of cells lying on top of the central region. The data indicated that there was only a small but steady increase in the total number of cells in the tissue, and for the model it was assumed that this occurred due to constant proliferation in the upper band.

As the upper band has a constant number of cells, the newly formed cells are assumed to immediately migrate into the central region where they will initially produce collagen. This implies that, since the proliferation rate in the upper band is unrestrained and hence constant, the resulting flux of cells into the central region from the upper band is constant and denoted by $\mathrm{F}_{\mathrm{NPro}}$ (for all other relevant equations and continuity conditions see Fig. 9). The regular refreshing of the medium will result in the GAGs being 
washed away from the upper surface and diffusing out through the filter membrane.

Throughout the whole structure the effect of cell death, due either to necrosis or apoptosis was neglected. The surrounding medium is rich in nutrients and is replaced regularly and hence is assumed to have constant properties. In addition, the size of the tissue remains relatively small throughout the experiment and thus the nutrient concentrations throughout the tissue will be always be high. Therefore, we assumed that the cells will always be able to obtain the energy they require for respiration and the raw materials necessary for ECM production.

The growth of tissue is a complicated process involving, for example, production of ECM constituents, generation of forces between cells, movement of cells through the ECM matrix, and remodelling of the ECM. For example, GAG induced swelling forces could contribute to tissue expansion (Nikolaev et al., 2010). However, in the mathematical model developed here a highly idealised behaviour was assumed with collagen providing the framework that determines the distance between cells. As collagen is produced by cells, the cells will move apart such that the density of collagen within the ECM remains constant. Alternative approaches with far greater mechanistic detail, such as for instance including the forces that develop during growth, would have complicated the model, but were expected not to significantly increase the insight into the general mechanisms involved.

Immediately after being seeded, the cells go through a settling period in which their characteristics greatly differ from those during the later stages of growth. This settling period was not modelled and the modelling simulations began at day seven.

In summary, the assumptions the mathematical model was based on were the following (including the mathematical modelling notation):

- The diameter of the filter is much greater than the thickness of the tissue layer; therefore the mathematical model needs to consider only variations through the thickness of the layer.

- The concentration of nutrients is high and uniform throughout the tissue layer.

- The lower and upper bands remain at a fixed thickness of $15 \mu \mathrm{m}$.

- The density of cells in the lower and upper bands is constant, at densities $\mathrm{N}_{\text {low }}$ and $\mathrm{N}_{\text {up }}$, respectively.

- Cells in the lower band are quiescent, thus not proliferating or producing ECM.

- Cells in the upper band do not produce ECM, but do proliferate, releasing the newly formed daughter cells into the central region at a constant rate, $\mathrm{F}_{\mathrm{N} \text { Pro }}$.

- Cells in the central region do not proliferate or undergo necrosis or apoptosis.

- In the central region, newly produced cells first produce collagen and then differentiate at a rate $\mathrm{R}_{\text {dif }}$ into cells that produce GAGs.

- Collagen and GAGs will be synthesised by a cell at constant rates $\mathrm{R}_{\text {col }}$ and $\mathrm{R}_{\text {gag }}$.

- GAGs will diffuse at a rate $\mathrm{D}_{\text {gag }}$ and bind to other $\mathrm{GAGs}$ at a rate $\mathrm{R}_{\mathrm{agg}}$. Once bound, GAG will diffuse at a rate $\mathrm{D}_{\text {agg }}$.
- The volume growth rate of the tissue at any point is directly proportional to the rate of collagen production.

- Collagen does not diffuse through the tissue.

- Cells will, because of the small size of the neo-tissue, always have sufficient supply of nutrients.

The values of parameters described above are given in Table 1. The diffusion coefficients are representative values based on (Comper and Williams, 1987) which shows a range of the order $10^{-10}-10^{-14} \mathrm{~m}^{2} \mathrm{sec}^{-1}$ for proteoglycan aggregates. The remaining values were derived from the experimental results.

\section{Results}

\section{Experimental results}

The averaged thickness of the tissue slices (example shown in Fig. 2a) was calculated from the image analysis data and showed a linear increase over time (Fig. 2b). Similarly, the adjusted tissue slices (Fig. 3a) show a linear increase in the number of cells per slice over time (Fig. 3b). Interestingly, this is not the case in both the lower and upper bands, where the cell number is stable. Proliferation occurs solely in the upper band, with cells then migrating to the central region, which leads to an increase in cell numbers in that area (Fig. 3c). Furthermore, the total number of cells in the central region of the synthesised tissue increases (Fig. 3c), but the expansion of the tissue layer causes a decrease in the relative density of cells in the central region. After 14 $\mathrm{d}$ of culture, cell densities (which were calculated using the experimental cell numbers) in the lower $90 \mu \mathrm{m}$ of the tissue, formed on the filter, do not change (Fig. 4).

The accumulated mass of GAGs produced and retained by the tissue structure increased linearly with time (Fig. 5a). The same was true for the accumulated mass of GAGs released from the tissue into the culture medium (Fig. 5b).

\section{Comparison of mathematical model with experimental results}

The mathematical model that was developed is described in detail in Appendix A. Initially, the tissue has a high density of cells that produce collagen and GAGs and cause the tissue to expand rapidly, and consequently the cell density decreases within the central region. Cell differentiation then creates a zone of predominantly GAG producing cells in the lower part of the central region of the tissue (Fig. 6a). Within this zone collagen production is low and therefore the growth of the tissue is negligible. In the central region above this zone the flux of cells into the central region from the upper band results in a population of cells that predominantly produce collagen (Fig. 6b). Thus, close to the upper band the tissue continues to expand (Fig. 7) and the cell density continues to drop. Consequently, the sole contributor to the growth of the tissue layer is the region immediately beneath the upper band. Growth is determined by the rate at which cells proliferate to be released into the central region, the differentiation rate of cells, and the rate at which cells produce collagen.

The cells in the lower band and central region of the tissue have fully differentiated to cells that produce 


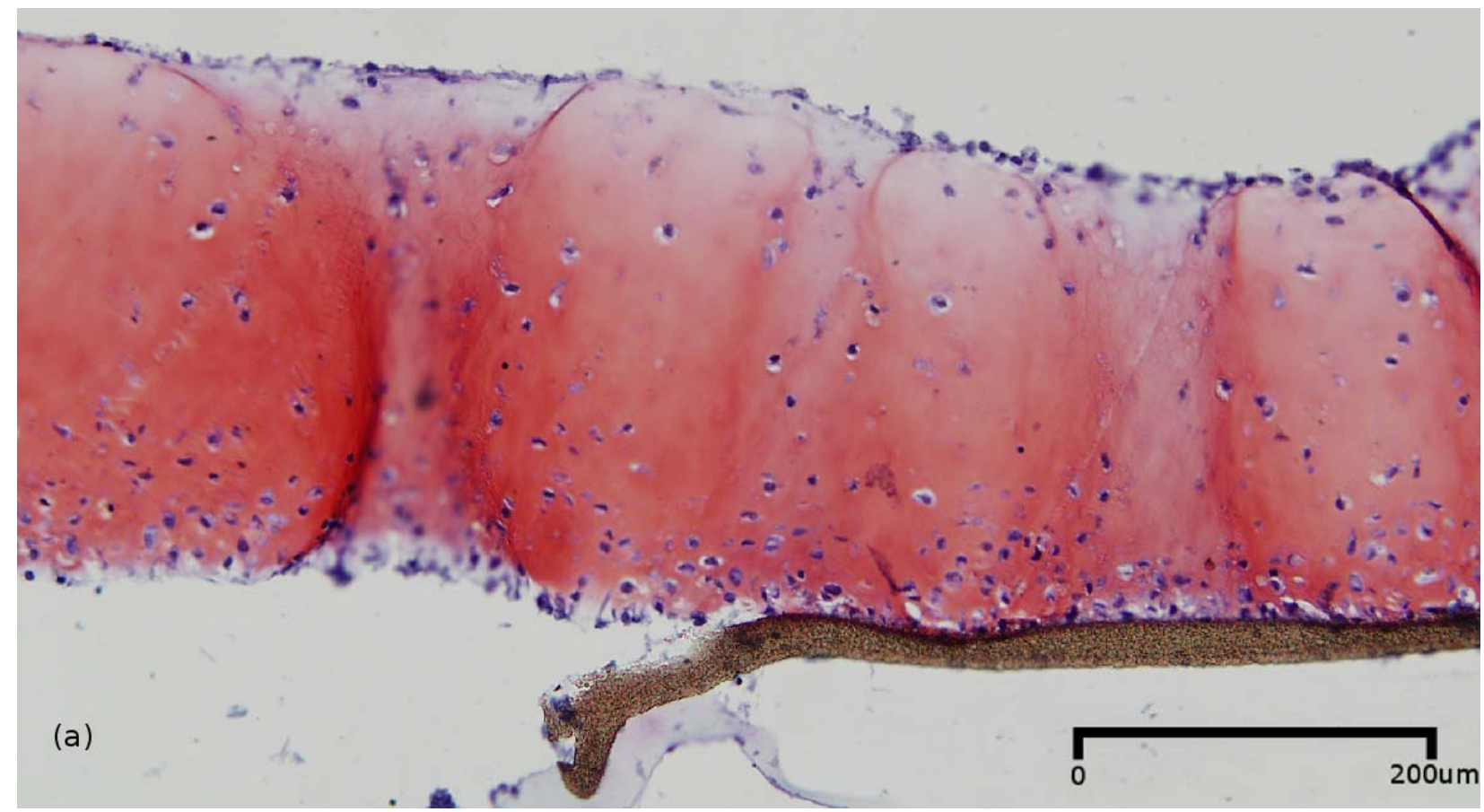

(b)

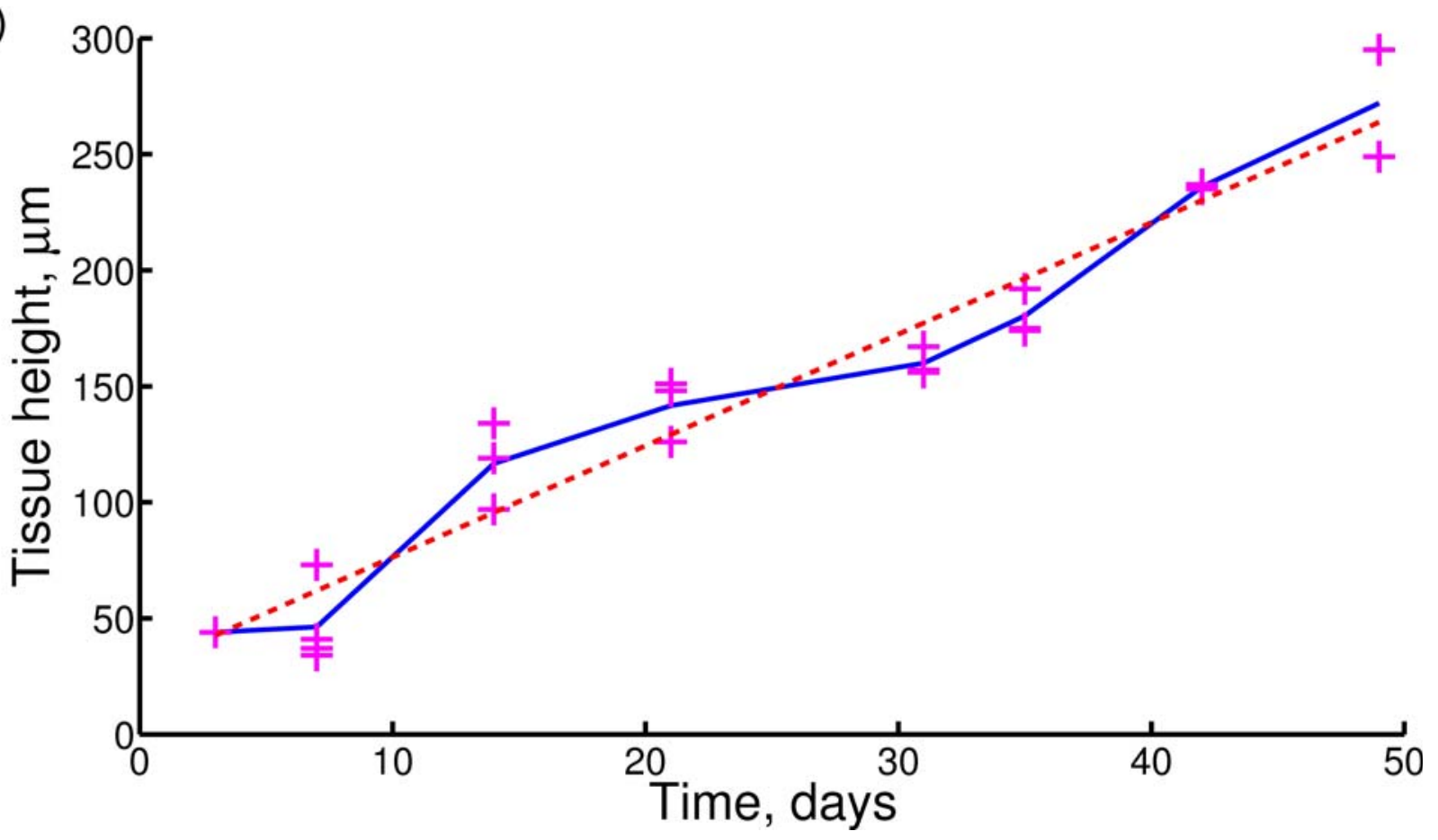

Fig. 2: (a) Safranin O staining of the tissue sample at $49 \mathrm{~d}$. The red staining indicates the presence of GAGs. The cells can be seen as darker dots, distributed throughout the tissue but with highest density at the surface of the filter membrane and at the surface of the tissue. The darker strip at the bottom is a remnant of the membrane. (b) Thickness of the tissue slices over time. The experimental data $(+)$, averaged data $(-)$ and a linear fit to the averaged data (- - -) are given. The average thickness of the tissue increases linearly with time $\left(\mathrm{R}^{2}=0.9675\right)$.

GAGs (Fig. 6a). This results in a high concentration of GAGs accumulating in the lower half of the tissue (Fig. 8a) and an even larger amount of GAGs being excreted from the tissue (Fig. 5b). GAGs are excreted from the tissue through both upper and lower boundaries. Due to the higher concentration of GAGs close to the filter membrane (Fig. 8a), the amount of GAGs diffusing out of the upper surface is similar to that diffusing from the lower surface through the filter membrane (Fig. 5b), despite the fact that some inhibition of GAG diffusion by the filter may occur. By implementing the appropriate parameter values, the mathematical simulations can generate data that comply with the experimental measurements for both GAG production and the amount of GAGs retained by the 


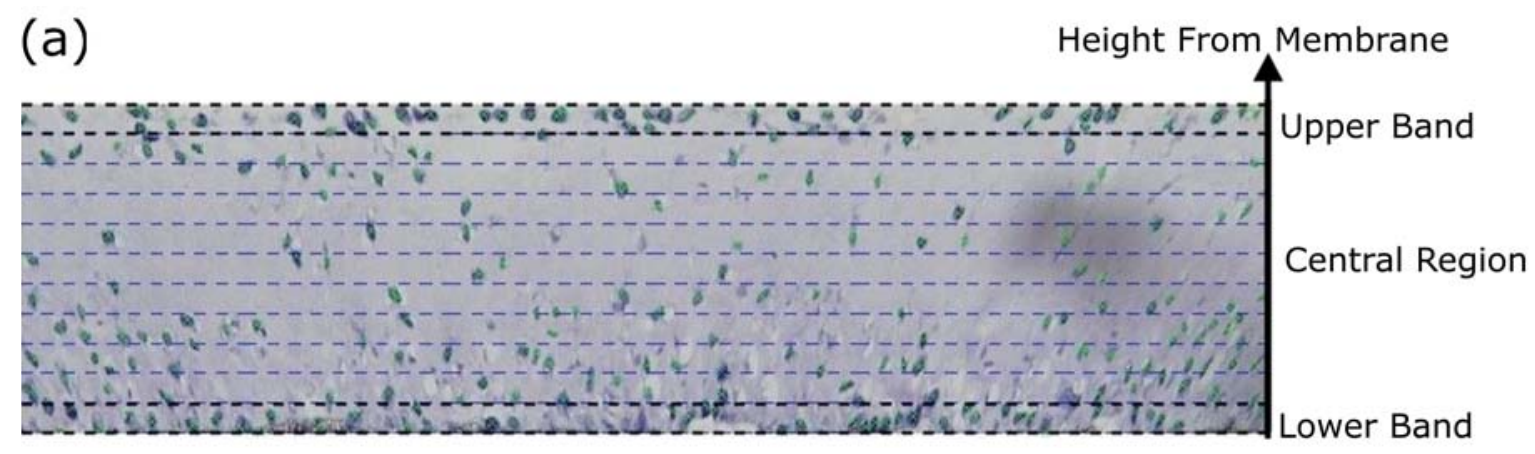

(b)

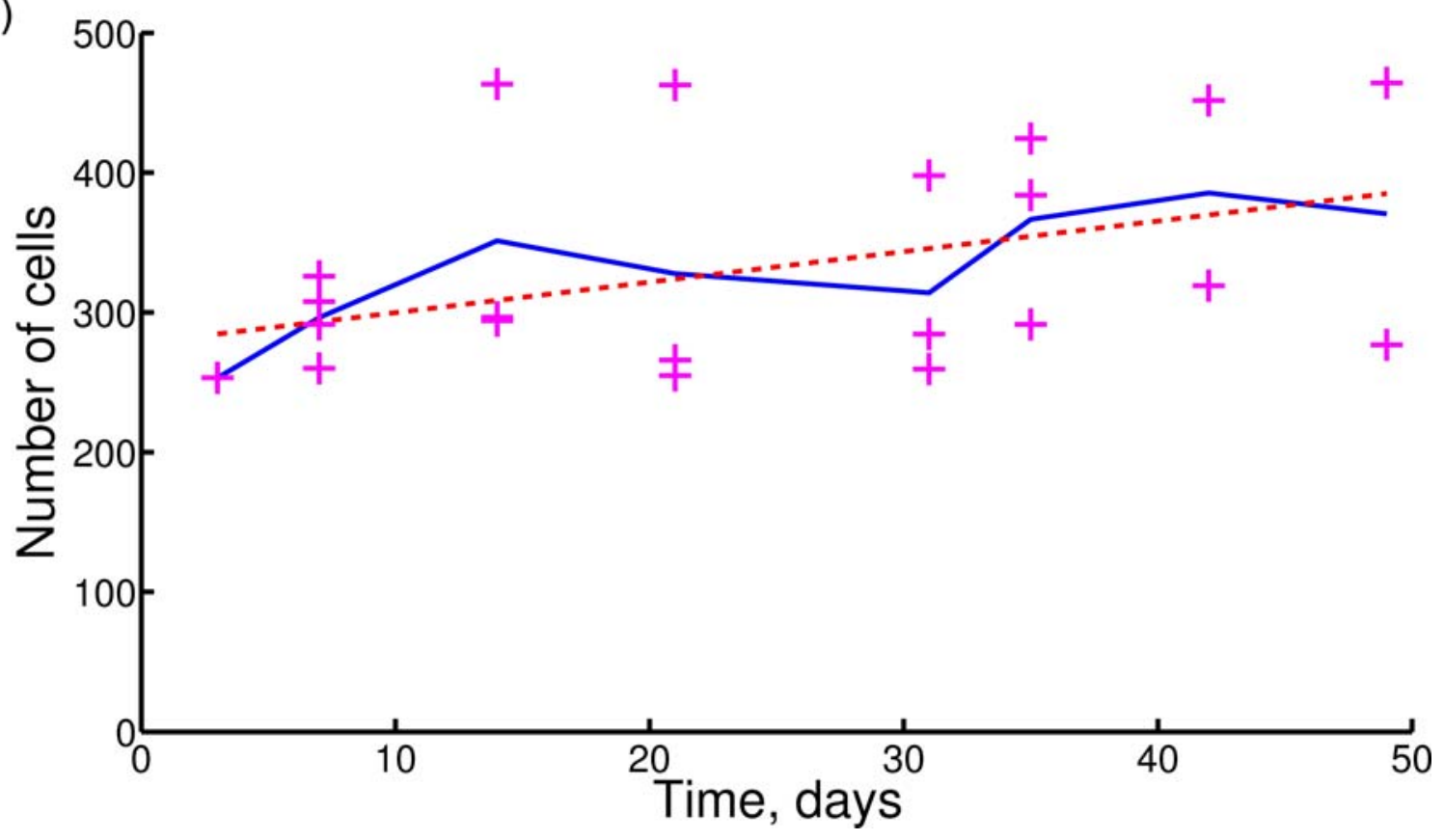

(c)

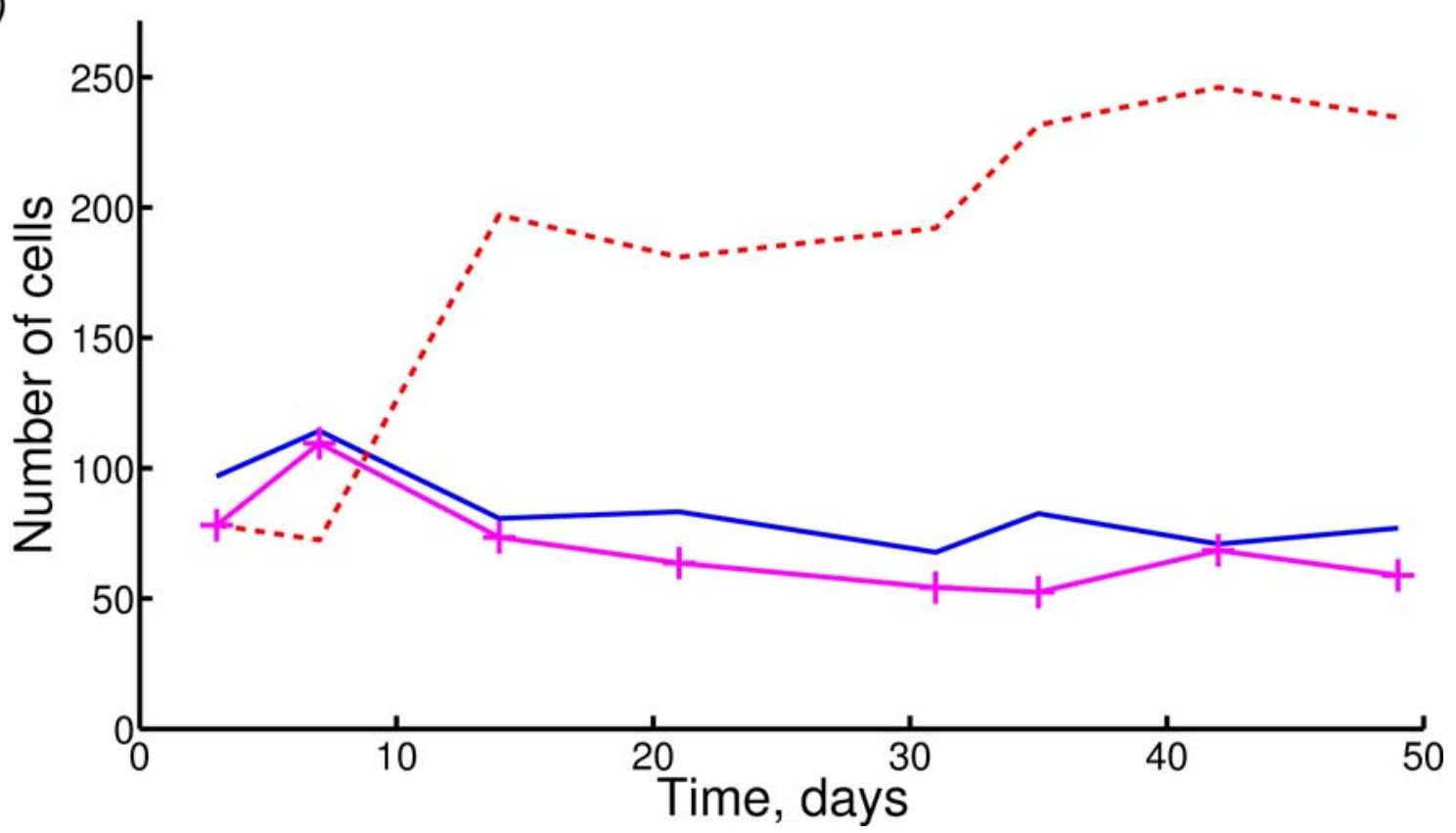

Fig. 3: (a) A sample of an analysed slice of tissue. The slice has been straightened and scaled to show the number of cells in the different regions of the tissue. The upper and lower bands are $15 \mu \mathrm{m}$ wide. The central layer increases in thickness over time. (b) The number of cells per tissue slice over time. The experimental data $(+)$, averaged data $(-)$ and a linear fit to the averaged data (- - ) are given. The average number of cells per slice increases approximately linearly with time $\left(\mathrm{R}^{2}=0.6764\right)$. (c) Experimental data showing the number of cells in the lower and (-) upper 15 $\mu \mathrm{m}$ band (-+-) and in the central region (- - ). The number of cells in the lower and upper bands is relatively constant, whilst the number in the central region increases. 


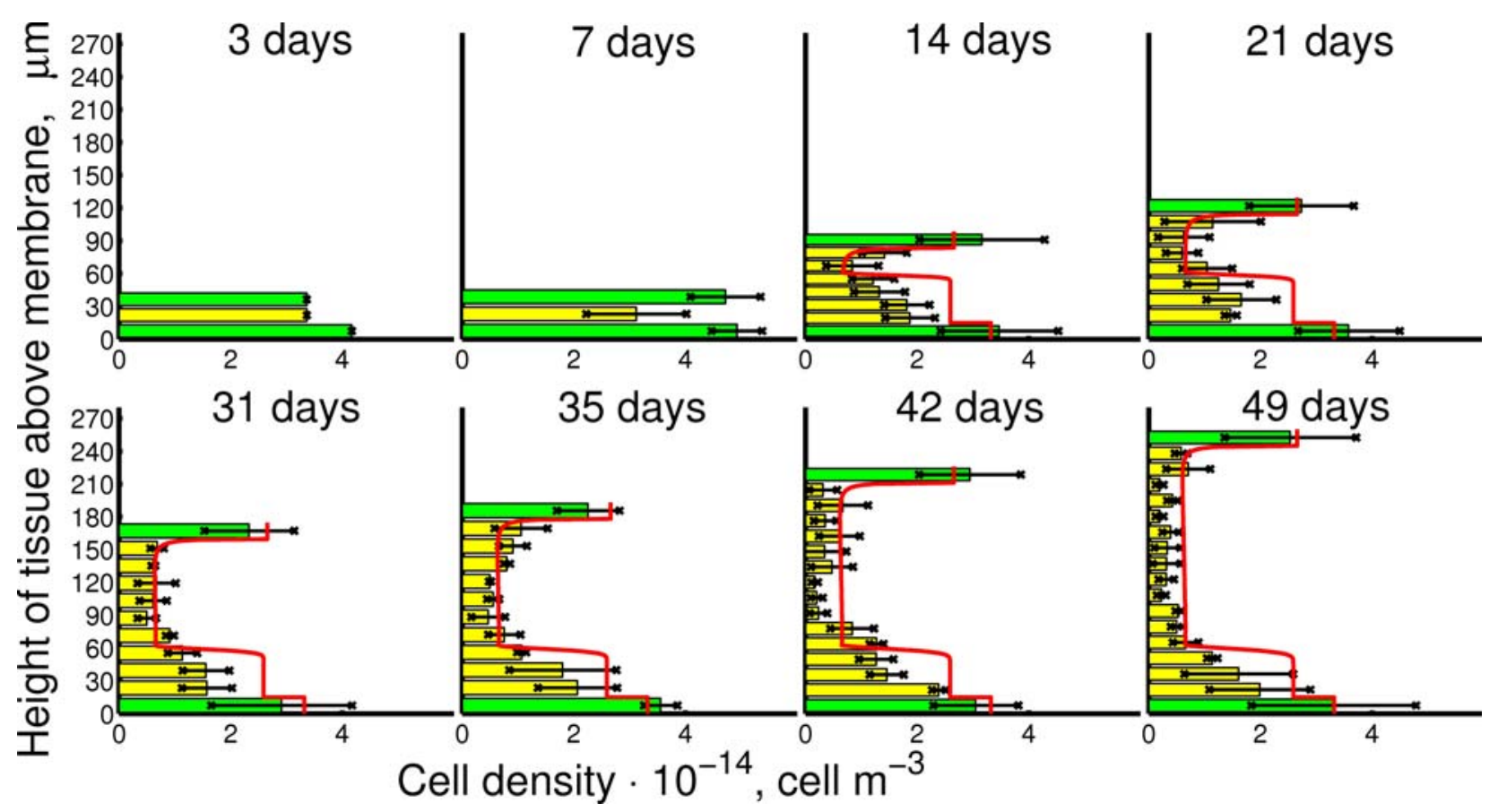

Fig. 4: Density of cells within the tissue samples over time. The histograms show the averaged experimental data with the standard deviations (note there is only a single data point for day 3 ); the continuous line represents the results of the mathematical model. The lowest bar of each histogram represents the cell density next to the membrane in the lowest $15 \mu \mathrm{m}$ layer. The highest bar represents the cell density in the upper $15 \mu \mathrm{m}$ layer next to the tissue surface. The bars in between represent the cell density in the central layer. The thickness of each band in the histograms is approximately $15 \mu \mathrm{m}$. After $14 \mathrm{~d}$ the cell densities in the lowest six bands remain constant. The mathematical simulations match the experimental results well and show that growth is confined to a region close to the upper band.

tissue construct (Fig. 5a). The experimental results show that GAG concentration is highest in the lower half of the tissue and less at the upper and lower boundaries of the tissue. The mathematical simulations confirm this trend, but show a lower value of GAG concentration near the lower boundary (Fig. 8b). According to the mathematical model, the overall rate of collagen synthesis, which facilitates separation of the cells, varies through the tissue layer. The cells near the tissue boundaries do not produce any substantial amount of ECM.

The mathematical simulations replicate the experimental data with respect to the distribution of cells (Fig. 4). Both show the lower band with a constant density of cells and a central region above this area that expands at a nearly constant rate. To more fully explore the resulting trends in the model behaviour a highly simplified version of the mathematical model was considered where a very narrow layer immediately below the upper band was considered to travel at constant speed. This travelling wave analysis neglects the GAG and is shown in Fig. 10. The solution to this model can be found analytically by changing to coordinates travelling at the constant speed and solving the resulting ordinary differential equations on the infinite region, as indicated on the left of Fig. 10. From this simplified model we find that the thickness grows at a speed given by

$$
\dot{S}=\frac{F_{\text {NPro }}}{N_{\text {up }}}\left(1+\frac{N_{\text {up }} R_{\text {col }}}{\operatorname{Col}_{0} R_{\text {diff }}}\right) \dot{S} \approx \frac{F_{\text {N Pro }} R_{\text {col }}}{\operatorname{Col}_{0} R_{\text {diff }}}
$$

and the growth is primarily in a layer immediately under the upper band of thickness

$$
\frac{\dot{S}}{R_{\text {diff }}} \approx \frac{F_{N \text { Pro }} R_{\text {col }}}{\operatorname{Col}_{0} R_{\text {diff }}^{2}}
$$

Using the same data as the full model, these simplified results give a speed of $4.3 \mu \mathrm{m} / \mathrm{d}$ and a narrow growth layer of $7 \mu \mathrm{m}$ thick. Here the two parts of the equation for the speed represent growth due to the additional tissue volume created by proliferating cells and the second part by the volume created by production of collagen to move cells apart. The approximations in the subsequent equations are based on the fact that growth due to cell division is negligible compared to the ECM production.

\section{Discussion}

We present a mathematical simulation that can accurately predict essential parameters of in vitro cartilage tissue growth on filter cultures. Photographs of experimental samples were analysed to determine the distribution and density of cells, thickness of the tissue layer, and distribution of GAGs in the tissue. In addition, GAG content and GAGs released into the culture medium were measured. Based on these values and on existing data from the literature regarding tissue formation, a mathematical model was formulated that could predict the density of 
(a)

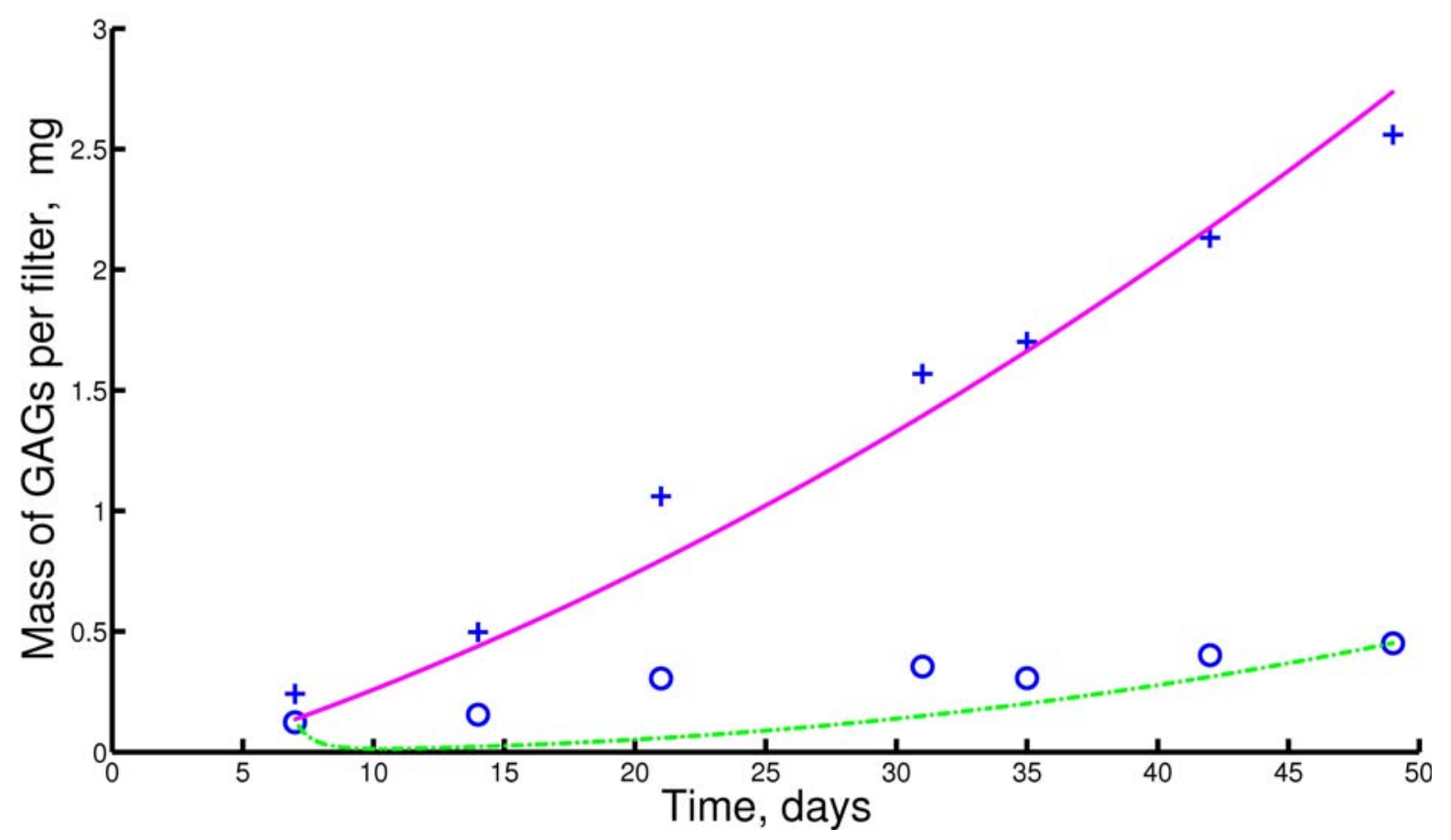

(b)

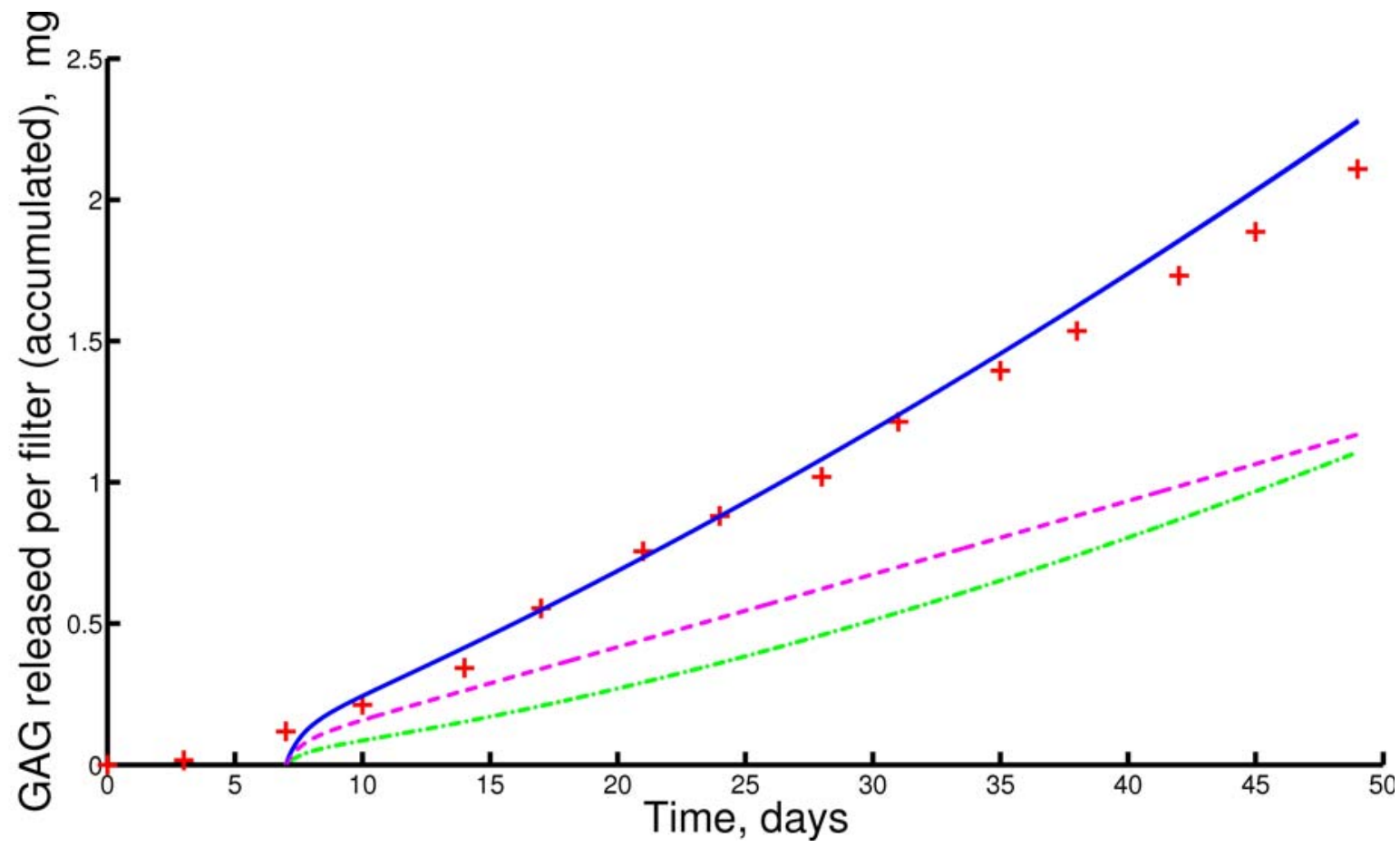

Fig. 5: (a) Accumulated amount of GAGs produced by the filter $(+)$ and the accumulated mass of GAGs that is retained in the tissue construct (o). Experimental data and results of the mathematical simulations (- and - -) are shown. The increase in the mass of GAGs produced and retained by the tissue construct is approximately linear. (b) Accumulated mass of GAGs released from the tissue layer. Experimental results $(+)$ and results of the mathematical simulation (-) are shown. The mathematical simulations for GAGs released through the filter membrane (--) and upper surface (-•) are also shown. The accumulated mass of GAGs released increased approximately linearly with time.

cells, production of collagen, production of GAGs, and the growth of the tissue layer, taking into account the effects of cell metabolism, cell differentiation, ECM production and structural growth.

Some interesting observations were made. The density of cells at both the lower and upper surfaces of the tissue remained constant and the amount of cells in the lower band of the tissue did not change after $14 \mathrm{~d}$. The thickness of the tissue, the average cell density, and the accumulated mass of GAGs released, all increased linearly over time. The absolute increase in thickness of the tissue was deemed insufficient to cause gradients in nutrient concentrations 
(a)

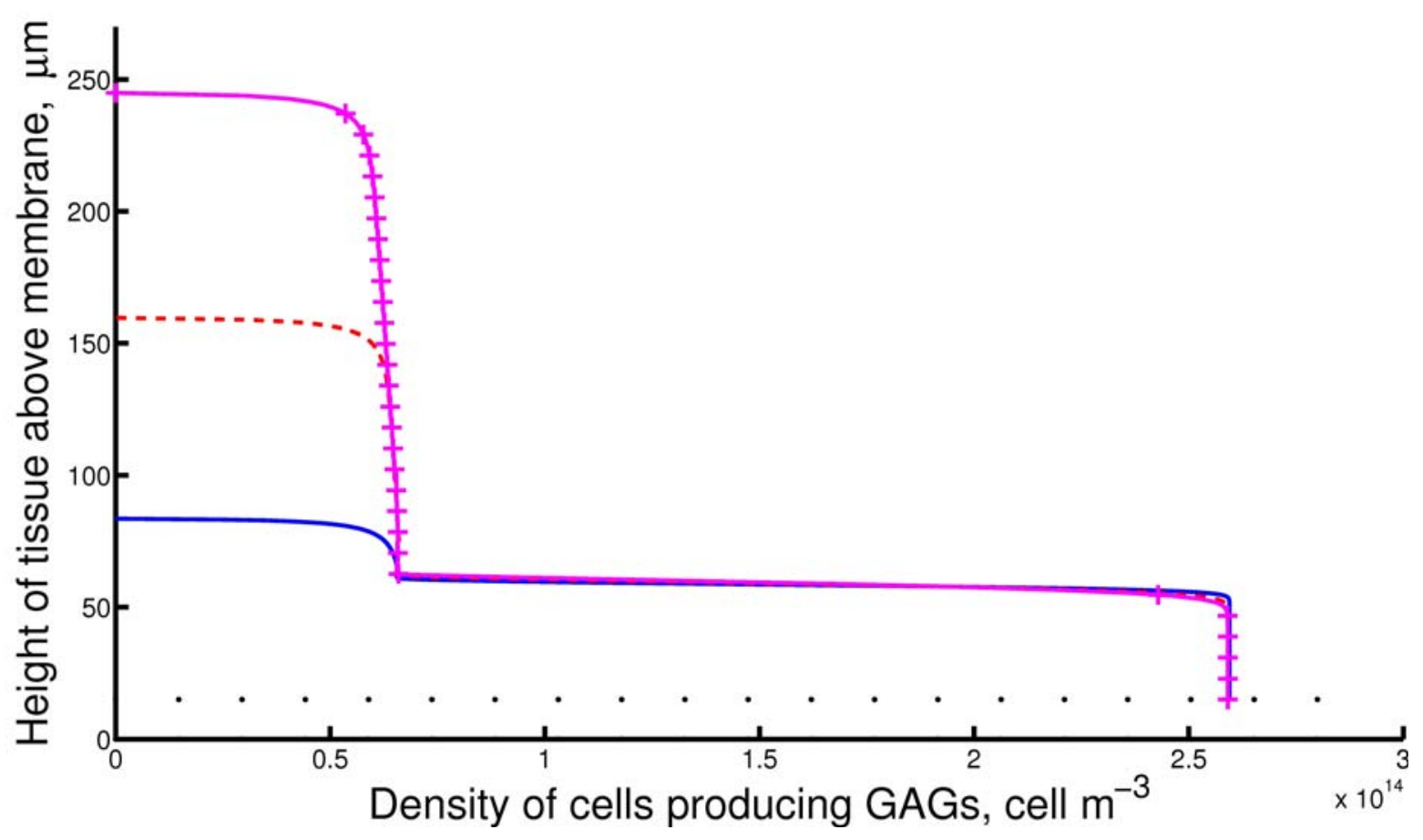

(b)

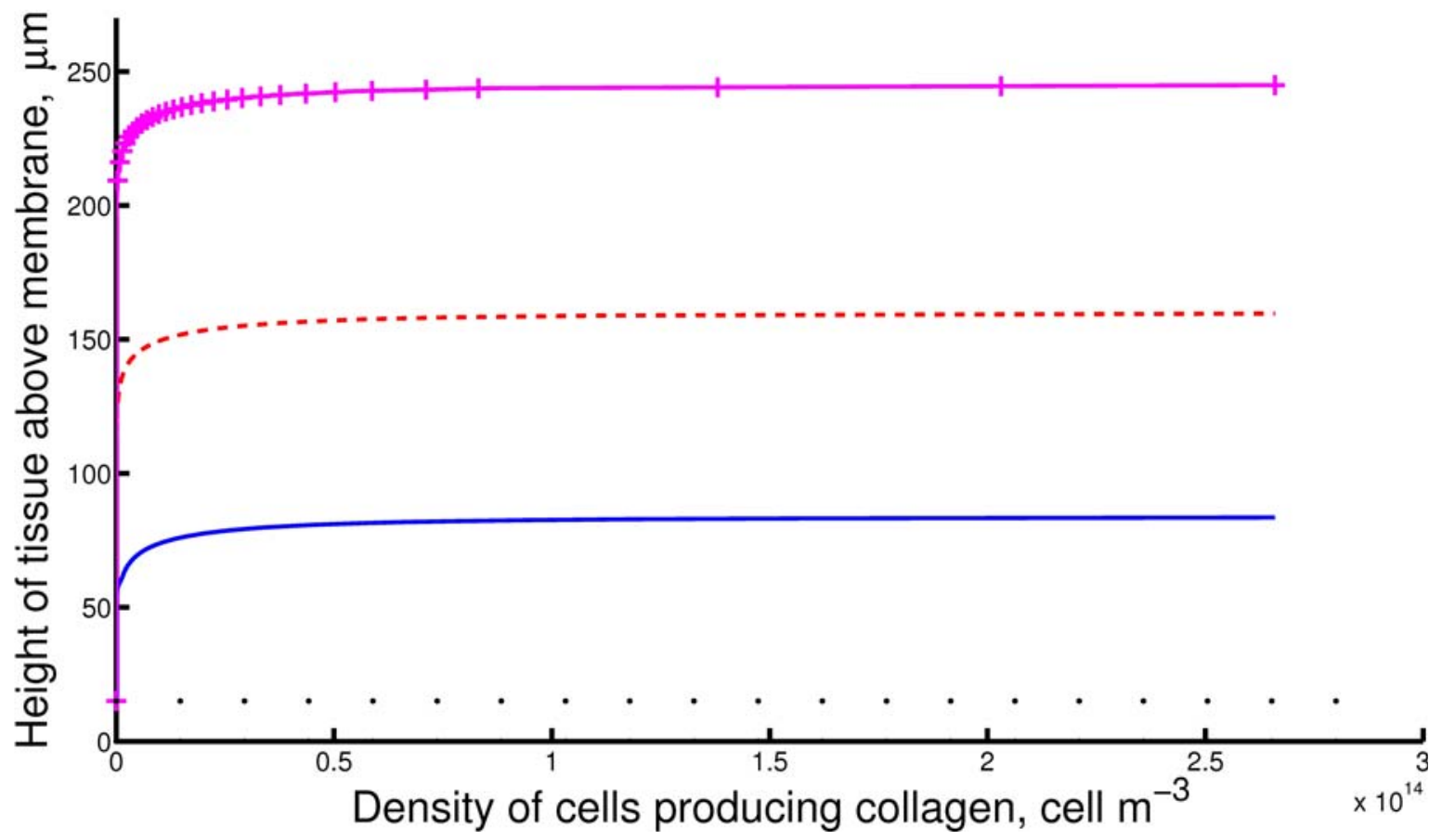

Fig. 6: (a) The density of GAG producing cells over the thickness of the central layer, as predicted by the mathematical model, at $14(-), 31(--)$ and $49 \mathrm{~d}(-+-)$. The newly formed cells quickly differentiate into cells that produce GAGs, leaving only a low density of GAG producing cells close to the upper layer of the tissue. The left hand section of the graph shows that the density of GAG producing cells in the upper layer of the tissue is relatively low. Subsequently, over a large segment of the tissue $(60 \mu \mathrm{m}$ and above) the density of GAG producing cells is relatively constant. In the middle part the lines are almost horizontal, indicating a very steep increase in GAG producing cells between 50 and $60 \mu \mathrm{m}$. In the far right hand section of the graph, it is shown that the density of GAG producing cells, in samples at all time points, is constant within the lowest $50 \mu \mathrm{m}$. (b) The density of cells producing collagen, as predicted by the mathematical model, through the central region at $14(-), 31(---)$ and $49 \mathrm{~d}(-+-)$. The cells rapidly differentiate so that only a small region of collagen producing cells is left close to the upper layer, where the maximum density of cells is equal to that in the upper layer, $2.66 \times 10^{14}$ cells $\mathrm{m}^{-3}$. In both graphs the lower layer is denoted by the horizontal dotted line. 


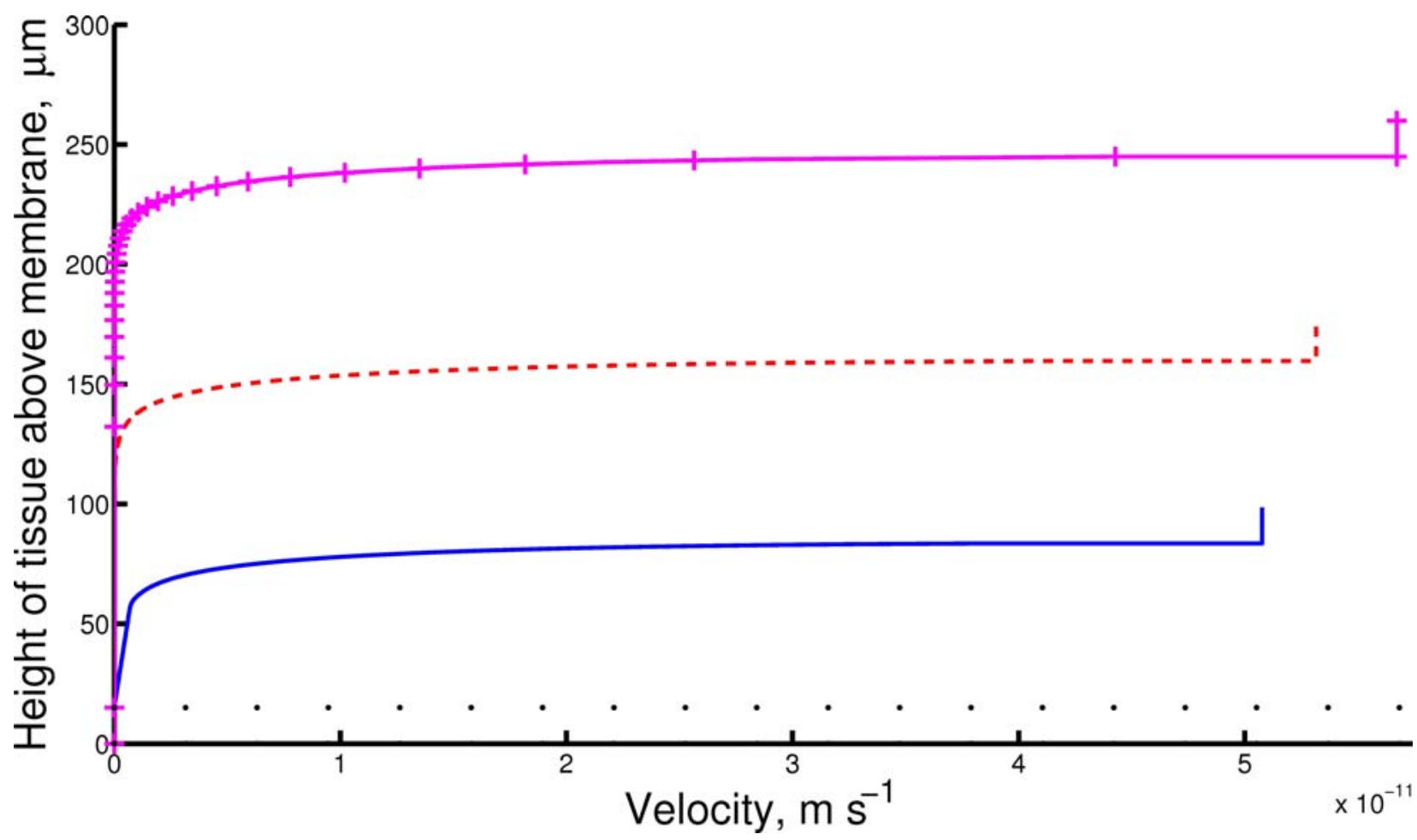

Fig. 7: The velocity of growth of the tissue layer, as predicted by the mathematical model, through the central region at $14(-), 31(---)$ and $49 \mathrm{~d}\left(-_{-}-\right)$. Growth is a consequence of collagen production in this model, thus the only region that is expanding is close to the upper layer. The lower layer is denoted by a horizontal dotted line.

that could potentially affect the growth characteristics (Malda et al., 2004).

This mathematical model shows that the growth of the tissue layer is limited to behaviour in a small region close to the upper surface. The thickness of this "growth layer", as can be seen from the simplified model, is defined by the differentiation rate of cells, the production rate of collagen, and the proliferation rate in the upper band, and is far less than the critical distance over which nutrients can diffuse. Furthermore, the mathematical model did not take into account confounding factors, such as cell death and ECM degradation. The equations have, however, the potential to be modified to incorporate these effects and thus to study larger tissue structures.

Neither the cells in the lower band nor in the upper band produced ECM, whilst the cells in the lower band were also shown not to proliferate. It is unlikely that this is a result of inefficient nutrient transport, as these two bands are very close to the culture medium that was replenished regularly.

The mathematical simulations confirm that large regions of the tissue are inactive with regard to proliferation and growth of the tissue layer. Cells in the lower half of the layer did not proliferate and ceased collagen production even at high concentrations of nutrients. Only a relatively small region close to the upper surface contributes to the expansion of the tissue and the increase in cell number. Interestingly, a similar phenomenon is observed during cartilage growth in vivo. In immature tissue, a pool of slowly dividing stem-like cells in the upper layers of the tissue (Dowthwaite et al., 2004) supplies the rapidly dividing daughter-cell pool that feeds the transitional and upper radial zones during the appositional growth of cartilage (Hayes et al., 2001; Hunziker et al., 2007). In mature tissue there are indications that the cells in the upper zones are better suited for the reorganisation of the zonal architecture of the native tissue compared to cells from the deeper zones (Hayes et al., 2005). Based on these observations and given the current efforts to regenerate the zonal architecture of the tissue (Klein et al., 2009), it can be concluded that the analysis of the temporal tissue development in filter cultures by cells derived from the different zones may be very helpful in generating greater insight into the differences between these cell populations. Apart from the behaviour of the different cell types, investigations could target the effects of different culture conditions, including varying glucose concentrations and different oxygen tensions and growth factor levels, which will most likely affect tissue architecture and development. This would further enhance our understanding of the mechanisms involved in the growth of cartilaginous tissue, and the mathematical simulations might in the future provide a means for the quick and efficient comparison and optimisation of different culture conditions.

During the first weeks of in vitro cartilaginous tissue neo-formation, collagen type VI is the main collagen, and is present throughout the matrix (Ofek et al., 2008). With time, it is replaced by collagen type II, and after 4 weeks, it is basically restricted to the pericellular area. Furthermore, the total amount of collagen decreases with time (Ofek et al., 2008). Because of these two characteristics, we chose not to differentiate between collagen types in our 
(a)

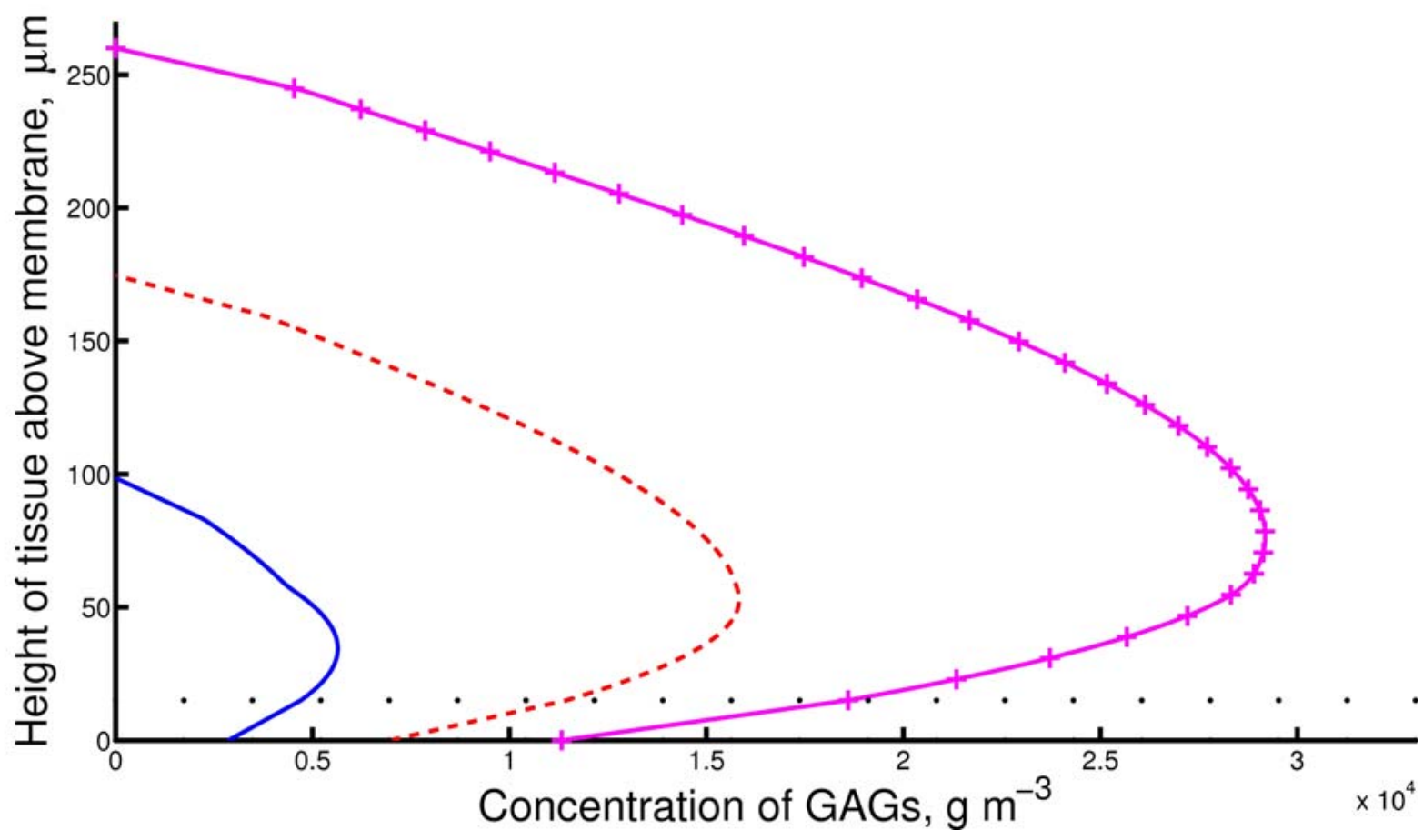

(b)

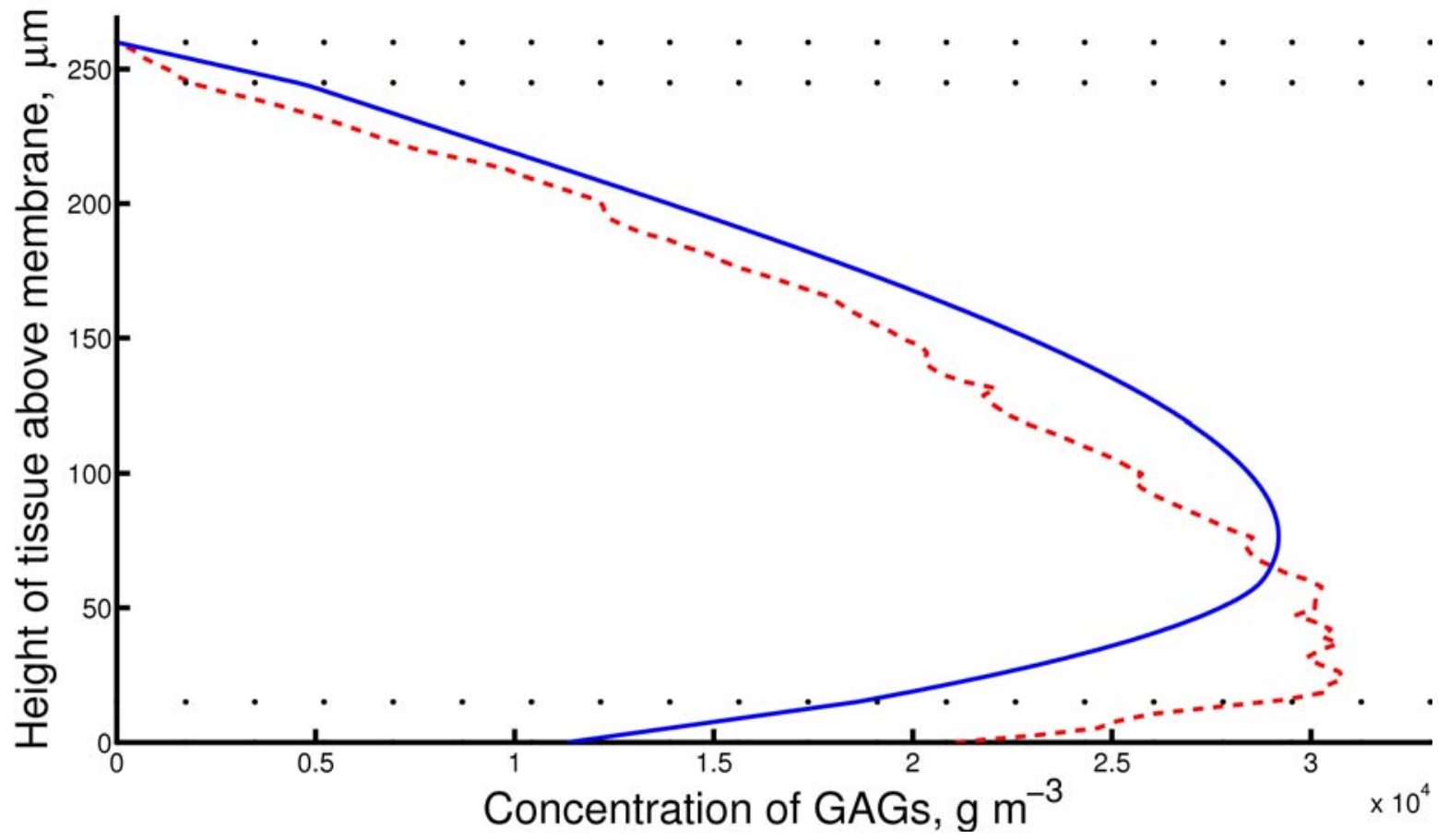

Fig. 8: (a) The concentration of unbound and aggregate GAGs through the tissue layer, as predicted by the mathematical model. Results are shown at $14(-), 31(--)$ and $49 \mathrm{~d}\left(-_{-}-\right)$. The filter membrane impedes the diffusion of GAGs from the tissue, thus the highest concentration of GAGs is found in the lower regions of the tissue, where the density of cells producing GAGs is also highest. (b) The distribution of GAGs through the tissue layer. A representative of the experimental results (--) and results of the mathematical simulation are shown at $49 \mathrm{~d}(-)$. The filter membrane is resisting the diffusion of GAGs from the lower boundary layer, whilst the GAGs on the top are 'washed' away by the medium. In both graphs the upper and lower bands are denoted by horizontal dotted lines.

mathematical model, but instead to consider the combined content of collagen types VI and II as the scaffold in which GAGs could spread. Gradually, the balance between collagen type VI and II in the scaffold shifts towards collagen type II.

Both the experimental results and the mathematical simulations contribute to the understanding of in vitro tissue growth. The characteristic distributions of cells and GAGs shown in this work have not been described previously. Further, the fact that growth of neocartilage apparently takes place in the upper half of the tissue, while the underlying regions remain relatively inactive, suggests an appositional growth rather than an interstitial growth. It has hitherto been presumed that in native cartilage growth 


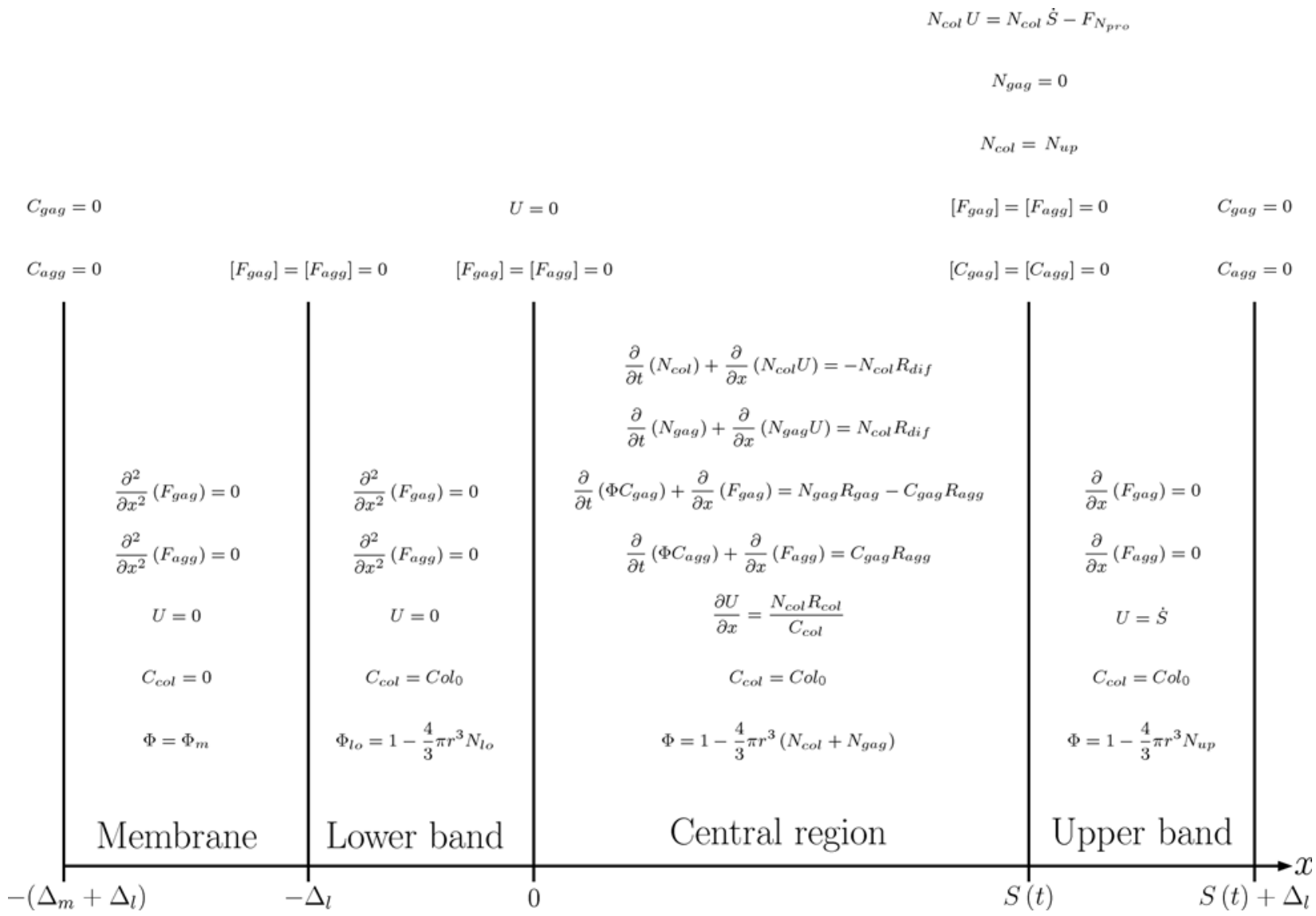

Fig. 9: Mathematical model of the four separate regions showing the relevant equations and continuity conditions between regions. Here the backets [ ] represent the jump in the quantity across a boundary. The fluxes in each region are given by $F_{i}=\Phi\left\{C_{i} U-D_{i} \frac{\partial C_{i}}{\partial x}\right\}$.

$$
N_{c o l} U=N_{c o l} \dot{S}-F_{N_{p r o}}
$$

$U \rightarrow 0$

$$
N_{c o l}=N_{u p}
$$

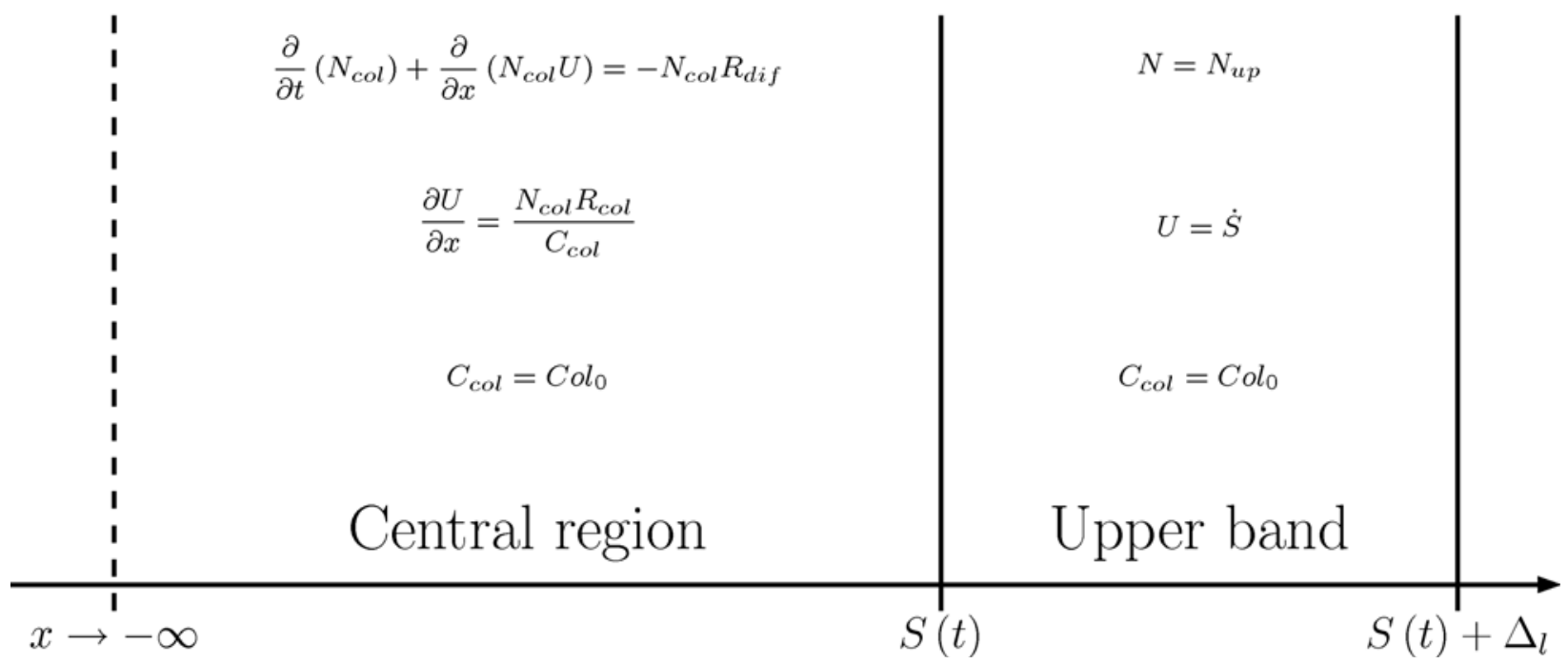

Fig. 10: Simplified mathematical model of the very narrow region just below the upper band showing the relevant equations and continuity conditions between regions. 
occurs via a combination of appositional and interstitial growth (Williams et al., 2008). Our data show that cell behaviour in the superficial zones is most critical to growth, which has important implications for the engineering of tissue growth. This would indicate that higher seeding densities in filter culture may not result in significant benefits, in line with observations by Hayes and colleagues (Hayes et al., 2007). In addition, the model indicates directions for future experiments to provide further validation, for example by using biochemical stimulation to modulate the differentiation rate to investigate how this affects growth. The simplified model shows clearly that a faster differentiation rate from collagen producing phenotypes to GAG producing phenotypes will result in a smaller zone where collagen is created just below the upper region and that this will reduce the growth rate of the layer. Similarly, reducing the proliferation rate in the upper layer will reduce the number of collagen producing cells and reduce the growth rate.

For the mathematical model used in this study several assumptions were made. These assumptions may need refining in future simulations as more experimental data becomes available, in particular with respect to the mechanisms of collagen production, cell differentiation and ECM construction, thus providing further insight into the natural development of the tissue layer.

\section{Conclusion}

The mathematical simulations developed in this study showed a good correlation with the results from the tissue cultures. It was shown that the thickness of the tissue increases at a constant rate due to the local expansion of the tissue close to the upper tissue surface, as opposed to uniform growth throughout. The restriction of growth to regions close to the tissue surface is governed by the rate at which cells change from a state dominated by the production of matrix components allowing rapid tissue expansion (e.g. collagen), to a state characterised by slower growth and higher production of GAGs. It was shown that GAGs were excreted at a constant rate due to diffusion and dependent on the aggregation rate. There are large regions within the tissue that are quiescent and where growth is negligible. It is concluded that the use of mathematical models can closely replicate experimental data, and hence are useful for the interpretation and understanding of culture systems. Mathematical modelling may offer significant potential for the optimisation of cartilage regeneration strategies.

\section{References}

Comper WD, Williams RP (1987) Hydrodynamics of concentrated proteoglycan solutions. J Biol Chem 262: 13464-13471.

Davies CdeL, Berk DA, Pluen A, Jain RK (2002) Comparison of IgG diffusion and extracellular matrix composition in rhabdomyosarcomas grown in mice versus in vitro as spheroids reveals the role of host stromal cells. Br J Cancer 86: 1639-1644.

DiMicco MA, Sah RL (2003) Dependence of cartilage matrix composition on biosynthesis, diffusion and reaction. Transport Porous Media 50: 57-73.

Dowthwaite GP, Bishop JC, Redman SN, Khan IM, Rooney P, Evans DJ, Haughton L, Bayram Z, Boyer S, Thomson B, Wolfe MS, Archer CW (2004) The surface of articular cartilage contains a progenitor cell population. J Cell Sci 117: 889-897.

Farndale RW, Buttle DJ, Barrett AJ (1986) Improved quantitation and discrimination of sulphated glycosaminoglycans by use of dimethylmethylene blue. Biochim Biophys Acta 883: 173-177.

Freed L, Hollander A, Martin I, Barry J, Langer R, Vunjak-Novakovic G (1998) Chondrogenesis in a cellpolymer-bioreactor system. Exp Cell Res 240: 58-65.

Galban CJ, Locke BR (1997) Analysis of cell-growth in a polymer scaffold using a moving boundary approach. Biotechnol Bioeng 56: 422-432.

Guo J, Jourdian GW, Maccallum DK (1989) Culture and growth characteristics of chondrocytes encapsulated in alginate beads. Connect Tissue Res 19: 277-297.

Hayes AJ, MacPherson S, Morrison H, Dowthwaite G, Archer CW (2001) The development of articular cartilage: evidence for an appositional growth mechanism. Anat Embryol 203: 469-479.

Hayes AJ, Hall A, Cheung I, Brown L, Tubo R, Caterson B (2005) Surface zone but not deep zone chondrocytes reorganize zonal architecture of articular cartilage grafts grown in vitro. Trans Orthop Res Soc 30: 1774.

Hayes AJ, Hall A, Brown L, Tubo R, Caterson B (2007) Macromolecular organization and in vitro growth characteristics of scaffold-free neocartilage grafts. J Histochem Cytochem 55: 853-866.

Hunziker EB, Kapfinger E, Geiss J (2007) The structural architecture of adult mammalian articular cartilage evolves by a synchronized process of tissue resorption and neoformation during postnatal development. Osteoarthritis Cart 15: 403-413.

Kato Y, Iwamoto M, Koike T, Suzuki F, Takano Y (1988) Terminal differentiation and calcification in rabbit chondrocyte cultures grown in centrifuge tubes: regulation by transforming growth factor beta and serum factors. Proc Natl Acad Sci U S A 85: 9552-9556.

Klein TJ, Malda J, Sah RL, Hutmacher DW (2009) Tissue engineering of articular cartilage with biomimetic zones. Tissue Eng B 15: 143-157.

Klisch SM, Asanbaeva A, Oungoulian SR, Masuda K, Thonar EJ, Davol A, Sah RL (2008) A cartilage growth mixture model with collagen remodeling: validation protocols. J Biomech Eng 130: 031006.

Malda J, Rouwkema J, Martens DE, Le Comte EP, Kooy FK, Tramper J, van Blitterswijk CA, Riesle J (2004) Oxygen gradients in tissue-engineered PEGT/ PBT cartilaginous constructs: measurement and modeling. Biotechnol Bioeng 86: 9-18.

Martin I, Obradovic B, Freed LE, VunjakNovakovic G (1999) Method for quantitative analysis of glycosaminoglycan distribution in cultured natural and engineered cartilage. Annal Biomed Eng 27: 656-662. 
Millipore (2009) Millicell cell culture insert. http:// www.millipore.com/catalogue/item/picm01250.

Nikolaev NI, Obradovic B, Versteeg HK, Lemon G, Williams DJ (2010) A validated model of GAG deposition, cell distribution, and growth of tissue engineered cartilage cultured in a rotating bioreactor. Biotechnol Bioeng 105: 842-853.

Obradovic B, Meldon JH, Freed LE, Vunjak-Novakovic G (2000) Glycosaminoglycan deposition in engineered cartilage: experiments and mathematical model. AIChE J 46: 1860-1871.

Ofek G, Revell CM, Hu JC, Allison DD, Grande-Allen KJ, Athanasiou KA (2008) Matrix development in selfassembly of articular cartilage. PLoS One 3: e2795.

Park K, Huang J, Azar F, Jin RL, Min BH, Han DK, Hasty K (2006) Scaffold-free, engineered porcine cartilage construct for cartilage defect repair in vitro and in vivo study. Artif Organs 30: 586-596.

Rouwkema J, Gibbs S, Lutolf MP, Martin I, VunjakNovakovic G, Malda J (2011) In vitro platforms for tissue engineering: implications for basic research and clinical translation. J Tiss Eng Regen Med 5: e164-e167.

Schinagl RM, Gurskis D, Chen AC, Sah RL (1997) Depth-dependent confined compression modulus of fullthickness bovine articular cartilage. J Orthop Res 15: 499-506.

Sengers BG (2005) Modeling the development of tissue engineered cartilage. $\mathrm{PhD}$ thesis, Technische Universiteit Eindhoven, The Netherlands

Sengers BG, Taylor M, Please CP, Oreffo RO (2007) Computational modelling of cell spreading and tissue regeneration in porous scaffolds. Biomaterials 28: 19261940 .

Stockwell RA (1971) The interrelationship of cell density and cartilage thickness in mammalian articular cartilage. J Anat 109: 411-421.

Taylor DW, Ahmed N, Gan L, Gross AE, Kandel RA (2009) Proteoglycan and collagen accumulation by passaged chondrocytes can be enhanced through side-byside culture with primary chondrocytes. Tissue Eng A 16: 643-651.

Williams GM, Klisch SM, Sah RL(2008) Bioengineering cartilage growth, maturation, and form. Pediat Res 63: 527534.

Yang KGA, Saris DBF, Geuze RE, Helm YJ, Rijen MH, Verbout AJ, Dhert WJ, Creemers LB (2006a) Impact of expansion and redifferentiation conditions on chondrogenic capacity of cultured chondrocytes. Tissue Eng 12: 2435-2447.

Yang KGA, Saris D, Verbout A, Creemers L, Dhert W (2006b) The effect of synovial fluid from injured knee joints on in vitro chondrogenesis. Tissue Eng 12: $2957-$ 2964.

\section{Discussion with Reviewers}

Reviewer II: In its current form, the model incorporates cell differentiation as a rate constant rather than a dependent variable. Are there any precedents in the literature for modelling cell differentiation mathematically in terms of independent variables, such as the presence/ concentration of growth factors? What information about this culture system would be required to ultimately describe neocartilage growth in terms of such independent variables?

Authors: Previous modelling has considered a differentiation rate to be implicitly linked to GAG and collagen production rates. These rates are conventionally taken to be either constant or dependent on the local oxygen or nutrient concentrations. Indeed, there are a few papers that consider dependency on growth factors (for example, Saha et al. (2004) and Zang et al. (2009)). In order to include such effects in a model, it would be necessary to determine the local growth factor concentrations that the cells will experience, as well as the cell response to these. Hence, information would be required on growth factor transport, dynamics, binding and trafficking, as well as adequate quantification of signalling pathways directing differentiation.

Reviewer II: Since neotissue thickness during the culture period was deemed insufficient to cause gradients in nutrient concentration, this model assumed that cell death was negligible during the 7-week culture. However, using the Live/Dead kit (for viability/cytotoxicity), Hayes et al. (2007) reported some death within filter cultures of bovine chondrocytes. Also, in other scaffold-free systems such as the pellet culture model, apoptosis is known to occur during neotissue maturation (Ichinose et al., 2010). How might future versions of the model account for the individual contributions of proliferation and apoptosis to overall cell number within the tissue layers? This could help extend the model into the "settling" period of neotissue development. Authors: The work by Ichinose et al. (2010) states "TUNEL positive cells (Figure 6c) and apoptotic cell death (Figure 6d) were observed sporadically in the middle zone of bone marrow- and synovium-MSCs, but could hardly be seen in chondrocytes." This appears to be in agreement with our neglect of such effects for the chondrocytes in our system. However, apoptotic behaviour could readily be incorporated into the model, once this is confirmed experimentally. This would then require experimental quantification and the identification of potential controlling mechanisms. We do agree that extending the model to account for behaviour that occurs within the settling period is an important future direction for the research.

\section{Additional References}

Ichinose S, Muneta T, Koga H, Segawa Y, Tagami M, Tsuji K, Sekiya I. (2010) Morphological differences during in vitro chondrogenesis of bone marrow-, synovium-MSCs, and chondrocytes. Lab Invest 90: 210-221.

Saha AK, Mazumdar J, Kohles SS (2004) Prediction of growth factor effects on engineered cartilage composition using deterministic and stochastic modeling. Ann Biomed Eng 32: 871-879.

Zhang L, Gardiner BS, Smith DW, Pivonka P, Grodzinsky AJ (2009) Integrated model of IGF-I mediated 
biosynthesis in a deformed articular cartilage. J Eng Mech 135: 439-449.

\section{Appendix}

The full system of equations used to mathematically model the tissue is shown in Fig. 9, with the physical description of the variables given in Table 2. The initial conditions used to solve the model are that at $\mathrm{t}=0, \mathrm{~N}_{\mathrm{col}}=\alpha_{\mathrm{cg}} \mathrm{N}_{0}$; $\mathrm{N}_{\text {gag }}=\left(1-\alpha_{\mathrm{cg}}\right) \mathrm{N}_{0} ; \mathrm{C}_{\mathrm{gag}}=0 ; \mathrm{C}_{\mathrm{agg}}=\mathrm{C}_{\mathrm{agg} 0}$ and $\mathrm{S}=\mathrm{S}_{0}$. All parameters used in the simulations are given in Table 1.

The system of equations, with corresponding boundary condition, defined in the filter membrane, the lower band and the upper band can be solved analytically. The system of modelling equations for the central region were solved numerically in MATLAB (The MathWorks, 2009). To incorporate the moving boundary the equations were transformed from the original expanding domain $\mathrm{x} \varepsilon[0$, $\mathrm{S}(\mathrm{t})]$ to a stationary coordinate frame, $\eta \varepsilon[0,1]$, using the transformation $x=\eta \mathrm{S}(\mathrm{t})$ and $\mathrm{t}=\tau$. The transformed system of equations was then rearranged into conservation form. Using a finite difference method the system of partial differential equations was discretised centrally in space. The backward Euler method was then used to discretise in time before solving at each time step using Newton's method. At each iteration the Jacobian was updated using Broyden's method. 